\section{Emprego em Saúde na Conjuntura Recente: Lições para a Reforma Sanitária*}

\author{
André Cezar Médici**
}

\section{INTRODUÇÃC}

O objetivo deste trabalho é detalhar algumas tendências já descritas por Nogueira ${ }^{6}$ sobre a dinâmica do emprego em saúde, na conjuntura da crise econômico-brasileira do qüinqüênio 1979-1984, bem como apontar alguns bloqueios, atualmente, existentes, no campo específico da política de recursos humanos em saúde, tendo em vista as bases para a Reforma Sanitária que vem sendo discutida por amplos segmentos da sociedade brasileira, desde a realização da VIII Conferência Nacional de Saúde.

Ao longo dos anos 70 ocorreu um forte crescimento do número de profissionais de saúde, bem como do quantitativo de empregos ligados ao setor. Este crescimento foi uma decorrência direta da reforma das instituiçōes da Previdência Social, em 1967, onde, a partir da unificação e extensão da assistência médica previdenciária a todos. os trabalhadores formais $1 *$, aumentou, sensivelmente, a demanda por serviços de saúde. Dado que esta demanda não poderia ser suprida pelo estoque de estabelecimentos prestadores de serviços até então existentes, no setor público, optou-se por uma política de contratação de prestadores privados. $\mathrm{O}$ aumento da demanda por serviços levou a um rápido crescimento da absorção de profissionais de saúde. Entre 1966 e 1974 o número de empregos, nas atividades hospitalares, passa de 150.123 para 303.098, destacando-se os postos de trabalho de nível médio e elementar e, em particular, os atendentes. Quanto aos profissionais de nivel superior a demanda passou a ser suprida pela larga expansão do aparelho formador. "Entre 1935 e 1965 o número de Escolas Médicas aumentou de 12 para 27 e o número de formados em medicina, de 8.184 para 15.754. A partir de 1965 foram autorizadas a funcionar 33 novas escolas de medicina, sendo a maioria delas no setor educacional privado"1. Esta grande ampliação do aparelho formador não correspondeu, no entanto, a uma adequação dos profissionais, às reais necessidades da população no campo médico-assistencial. Como resultado, grande parte do corpo médico formada nos anos 70 tem, como referência, uma medicina especializada, tecnificada, privatizante e totalmente distante do quadro social de saúde no Brasil.

Nas figuras do médico - este profissional especializado e tecnificado - e do atendente - mão-de-obra, sem especialização, capaz de aceitar os níveis salariais mais baixos ergueu-se a assistência médica privada dos anos 70 . Financiada tanto ao nível do investimento quanto ao nível do custeio pelo setor Cadernos de Saúde Pública, R.J., 2 (4): 409-422, out/dez, 1986
* Este trabalho é um subproduto da "Pesquisa sobre Recursos Humanos em Saúde 19761984" que está sendo desenvolvida no Departamento de Planejamento e Administração da ENSP/FIOCRUZ, sob coordenação do Prof. Mário Sayeg, com financiamento da Organização Pan-Americana da Saúde.

* Economista, Assessor-Che. fe da Diretoria de População e Social do IBGE e Professor e Pesquisador do ENSP/FIOCRUZ.

* Considera-se como trabalhadores formais aqueles que estaio protegidos por laços trabalhistas ou previdenciários, englobando os empregados com carteira de trabalho assinada ou os autónomos que contribuem para a previdencia social. 
* Programas criados na década de 70, com o Fundo de Apoio ao Desenvolvimento Social - FAS, foram importantes canais de expansäo da rede privada de serviços de saúde no Brasil; a partir de financiamentos, a construção de hospitais e clinicas com juros subsidiados. Quando prontos, estes estabelecimentos recebiam uma clientela cativa do INAMPS, que garantia sua sustenção financeira. Ao agir dessa forma, o Estado criou, ao longo dos anos 70 , verdadeiras reservas de mercado para os capitais privados no setor saúde.

* O termo sobre oferta de médicos está sendo usado no sentido de explicitar uma grande oferta desses profissionais em mercados de trabalho muito restritos. Em função da própria distribuição espacial dos segurados, cerca de $60 \%$ dos recursos humanos voltados a medicina previdenciária, estavam localizados no Sudeste, ao longo dos anos 70. Da mesma forma, o esttmulo d̀ especialização saturou, rapidamente, o mercado de trabalho em certas especialidades nas regiöes urbanas, em função da baixa correspondência entre formação de profissionais e demanda pelos serviços nestes ramos. Isto não significa que não existe, no Brasil, bolsão onde se observa a mais absoluta carência de profissionais em medicina, tanto do ponto de vista espacial, quanto nas especialidades básicas e mais gerais. público, Médici e Silva. ${ }^{5}$ A prática dos estabelecimentos privados tem sido responsável por grande parte dos problemas que, hoje, têm que ser enfrentados, no campo dos recursos humanos, em saúde. A utilização em massa, do atendente como um dos pólos da pirâmide ocupacional do setor, por exemplo, inibiu o desenvolvimento de estratégias mais arrojadas de formação de mão-de-obra específica (auxiliares e técnicos) ao nível de 2\% grau. Dado que, em média, $70 \%$ dos recursos públicos, em assistência médica, foram repassados ao setor privado, na década passada. Não havia nenhum estímulo à formação de um grande contingente de profissionais qualificados, de nível médio, com vistas a integrar as equipes hospitalares e para-hospitalares. A lógica do setor privado foi sempre rebaixar os salários dos profissionais de menor qualificação. Daí, a ênfase na utilização dos atendentes e o descaso pelos profissionais qualificados, de nível médio.

Outro problema que, em certo sentido, pode-se dizer "plantado" pelo setor privado contratado foi o da multiplicidade de empregos, especialmente, para o médico. A formação, em massa, de profissionais em medicina, ao longo da década de 70 foi, em certo sentido, adequada às estratégias de expansão do setor privado que tinha, na figura do médico, o outro pólo de suas equipes. O recurso à especialização formou, na prática, segmentos especiais de mercado de trabalho para cardiologistas, gastroenterologistas, ginecologistas, pediatras, etc. que, em função do rebaixamento salarial provocado pela sobre-oferta destes profissionais, forçava-os a combinar empregos em estabelecimentos públicos e privados com a prática autônoma (liberal), em consultórios. Vale dizer que o "multiemprego" do médico não foi, propriamente, uma "estratégia de sobrevivência", embora tenha sido uma regra de comportamento, cuja lógica calcava-se na sobre oferta artificial de profissionais médicos* e no ret uxamento do piso salarial, tanto no setor privado como no público. Entre 1970 e 1980, o número de formados em medicina passou de 45.113 para 101.793, e as Escolas Médicas estavam formando, em média, 8.000 profissionais/ano. Nos anos 80 , o número de egressos reduziu-se para o patamar de 7.200.

Esta sobre-oferta relativa, de médicos nas regiões urbanas, nas grandes metrópoles do Sudeste e em algumas especialidades é, no entanto, a contraface da carência absoluta de médicos em, pelo menos, $10 \%$ dos 4.100 municípios brasileiros. É o preço que a sociedade brasileira tem que pagar pela ausência de médicos generalistas ou formados nas especialidades básicas, e que possam atender e ecompanhar, indiscriminadamente, a situação de saúde, na maioria das famílias brasileiras, a exemplo do que ocorre em Cuba. É o legado que deixou o sistema de assistência médica montado, no Brasil, nestes últimos vinte anos: o enriquecimento relativo dos prestadores privados $\mathrm{X}$ o empobrecimento relativo da qualidade dos recursos humanos em saúde.

A política de saúde implementada nas duas últimas décadas levou, nos aos 70 , às seguintes tendências no que diz respeito aos recusos humanos alocados no setor: ${ }^{4}$ 
a) Crescimento acelerado da Força de Trabalho em Saúde, marcado por um incremento bruto de $125,31 \%$ do número de profissionais entre 1970 e 1980 . O setor saúde tem sido caracterizado, também, como um grande pólo de absorção de empregos. Em temos gerais, as categorias que mais cresceram, de forma absoluta, foram os médicos e o pessoal de enfermagem com nível médio e elementar, capitaneado pelos atendentes;

b) Aumento da participação feminina no emprego setorial, na medida em que a força de trabalho feminina, em saúde, passa de $41 \%$ para $63 \%$ do total dos profissionais do setor, ao longo da década ${ }^{3}$. Este fenômeno foi mais sensível entre os profissionais universitários, onde a participação feminina, entre 1970 e 1980 , elevou-se de $20 \%$ para $39 \%$;

c) Rejuvenescimento da Força de Trabalho em Saúde, dado que os profissionais, entre 20 e 29 anos de idade, passam de $30 \%$ a $36 \%$ do total de ocupados no setor, entre 1970 e 1980 , ocorrendo o inverso com os profissionais de idade superior a 60 anos. O rejuvenescimento está associado a fenômenos como a expansão universitária e o aumento da participação feminina, e explica, em parte, o rebaixamento dos salários médios no período;

d) Aumento do grau de escolaridade dos profissionais, marcado pelo aumento da magnitude relativa dos profissionais de nível superior, ao total da força de trabalho do setor e pela maior escolaridade adquirida pelos profissionais de nível médio e elementar, inclusive em formação específica;

e) Redução dos prestadores autônomos de serviços, que diminuem de $15,1 \%$ para $13,7 \%$, no conjunto de profissionais de saúde e de $42,8 \%$ para 33,6\%, para os profissionais de nível superior, ao longo do período. Tal redução decorre do aumento dos níveis de assalariamento, em conjunto com incrementos do exercício de múltiplas inserções no mercado de trabalho, como ocorre, mais, especificamente, com os médicos;

f) Aumento da absorção de empregos, no setor privado, decorrente, em termos mais gerais, da política de assistência médica implementada ao longo do período;

g) Prolongamento da jornada de trabalho, dos profissionais de nível superior, como decorrência do aumento da estratégia de inserções múltiplas no mercado de trabalho. Os dados relativos ao número de horas contratadas mostraram que $46,2 \%$, dos médicos, trabalhavam mais de 50 horas semanais, em 1980, enquanto que, em 1970, apenas $36,8 \%$ encontravam-se nesta posição. Como decorrência, $78,1 \%$ dos postos de trabalho dos médicos, em 1980, eram de tempo parcial;

h) Desconcentração e bimodalidade dos rendimentos dos ocupados em saúde, marcando, para os profissionais de nível superior, um conjunto de pessoas concentradas na faixa de renda de 5 a 10 salários mínimos, e com outros rendimentos entre 20 e 30 salários mínimos, em 1980. Os que se concentram na primeira faixa, geralmente, são jovens, mulheres e profissionais com jornada de trabalho inferiores a 40 horas semanais, e assalariados. Os que se concentram na outra são 
* Uma análise mais detalhada destas tendências pode ser encontrada nos trabalhos de Nogueira (1986); Machado (1986) e Médici (1984). profissionais com mais idade, homens, detentores de jornadas de trabalho superior a 40 horas semanais, e possuidores de destacadas posições na prática liberal*.

Todas estas tendências estão associadas ao padrão de organização do setor saúde, no Brasil, ao longo da década de 70. Mas o discurso e, até mesmo, as políticas de saúde implementadas, não são homogêneas, durante este período. Assim, "as políticas do emprego e recursos humanos em saúde passam a privilegiar, a partir de 1976, a formaçāo e capacitação de pessoal de nível técnico e auxiliar, sem qualificação superior, voltados para atender, prontamente, às necessidades da rede ambulatorial e, não somente, aos aparelhos hospitalares públicos e privados que haviam absorvido o maior quinhão dos recursos humanos em saúde, nos anos anteriores" 4 . Passam a enfatizar a formação de generalistas e, não somente, de especialistas como vinha ocorrendo desde finais dos anos 70 . Ressaltam a necessidade de criar políticas de formação e gerência de recursos humanos, nos moldes de serviços mais regionalizados e hierarquizados; tendência essa que se observa desde o PIASS, o PREV-SAÚDE, o CONASP e se corporifica, com toda as forças, nas Ações Integradas de Saúde.

Esta mudança na retórica da política de recursos humanos, pelos ministérios e demais órgãos ligados ao setor saúde, ocorreu no meio de mudanças mais profundas, nos estilos de condução estratégica e operacional do setor. Seus resultados, apesar de tímidos, começam a aparecer, a partir dos anos 70.

\section{EMPREGO EM SAÚDE NO BRASIL E A DINÂMICA DO SETOR PÚBLICO: 1976-1984}

O emprego em saúde, no Brasil, tem como determinante básico a dinâmica e a política de emprego do setor público, em particular, das políticas traçadas para o atendimento e operação das chamadas atividades sociais. Tal afirmação pode parecer paradoxal, quando observamos que, nos anos 70, a maior parcela dos estabelecimentos de atenção médica situava-se no setor privado. De fato, em 1978, a iniciativa privada concentrava $81,2 \%$ da rede de serviços de saúde, "com internação". Esta proporção reduziu-se para 78,6\%, em 1982 e, ao que se presume, continua a diminuir nos últimos anos, conforme pode ser observado na Tabela 1 . A hegemonia do setor privado, na atenção médica, não se verifica, nos estabelecimentos de saúde, de caráter ambulatorial, ou seja, sem internação. Esses, historicamente, vêm sendo mantidos, em larga escala, pelas Secretarias Estaduais e Municipais de Saúde, sendo, portanto, de natureza pública. Recentemente, os investimentos em programas como o PIASS e a expansão da rede de Postos de Assistência Médica do INAMPS têm realimentado esta hegemonia.

Em 1978, cerca de $70 \%$ dos estabelecimentos sem internação dos mais variados tipos (postos de saúde, centros de saúde, postos de vacinação, postos de assistência médica, etc.), Cadernos de Saúde Pública, R.J., 2 (4): 409-422, cut/dez, 1986 
eram públicos. Esta proporção aumentou para $79,8 \%$, em 1982 e, ao que parece, continuará a crescer, dadas as estratégias descentralizadoras voltadas para ação de menor complexidade, como as AIS.

O setor privado concentrava $51,0 \%$ do total de empregos em saúde, sendo que nos estabelecimentos com internação, essa proporção chegava a 62,5\%, em 1982.

$$
\begin{gathered}
\text { TABELA } 1 \\
\text { DISTRIBUIÇÃO DOS ESTABELECIMENTOS DE SAÚDE NO BRASIL, } \\
\text { SEGUNDO A NATUREZA DA ENTIDADE MANTENEDORA } \\
1978-1982
\end{gathered}
$$

\begin{tabular}{|c|c|c|c|c|c|c|}
\hline \multirow{3}{*}{$\begin{array}{c}\text { ANOS DE } \\
\text { REFERÊNCIA }\end{array}$} & \multicolumn{6}{|c|}{ NATUREZA DA ENTIDADE MANTENEDORA } \\
\hline & \multicolumn{2}{|c|}{ TOTAL } & \multicolumn{2}{|c|}{ PÚBLICA } & \multicolumn{2}{|c|}{ PRIVADA } \\
\hline & ABS & $\%$ & $\mathrm{ABS}$ & $\%$ & ABS & $\%$ \\
\hline \multicolumn{7}{|l|}{ TOTAL } \\
\hline 1978 & 15.345 & 100,0 & 7.839 & 51,1 & 7.506 & 48,9 \\
\hline 1980 & 18.489 & 100,0 & 10.045 & 54,3 & 8.444 & 45,7 \\
\hline 1982 & 24.017 & 100,0 & 15.290 & 63,7 & 8.727 & 36,3 \\
\hline \multicolumn{7}{|l|}{ COM INTERNAÇÃO } \\
\hline 1978 & 5.708 & 100,0 & 1.072 & 18,8 & 4.636 & 81,2 \\
\hline 1980 & 6.103 & 100,0 & 1.217 & 19,9 & 4.886 & 80,1 \\
\hline 1982 & 6.650 & 100,0 & 1.423 & 21,4 & 5.227 & 78,6 \\
\hline \multicolumn{7}{|l|}{ SEM INTERNAÇÃO } \\
\hline 1978 & 9.637 & 100,0 & 6.767 & 70,2 & 2.870 & 29,8 \\
\hline 1980 & 12.386 & 100,0 & 8.828 & 71,3 & 3.558 & 28,7 \\
\hline 1982 & 17.367 & 100,0 & 13.867 & 79,8 & 3.500 & 20,2 \\
\hline
\end{tabular}

Fonte: IBGE, Pesquisa de Assistência Médico-Sanitária, 1978-1982

Já em 1984, o setor privado perdeu a hegemonia na totalidade do emprego em saúde, passando a abarcar $47,7 \%$ do total. A té mesmo nos estabelecimentos com internação, a participação privada vem declinando. Em 1984, os estabelecimentos públicos com internação, já concentravam $41,0 \%$ do emprego hospitalar do país (Tabela 2).

Assim, tudo indica que a tendência à privatização, verificada nos anos 70, marcada pela concentração de profissionais de saúde, nos estabelecimentos privados, esteja sendo revertida, na década de 80.

Quando se afirma, portanto, que a dinâmica do emprego e dos investimentos, no setor público, é que determina o nível de ocupação e as condições de trabalho nas entidades, tem-se que levar em conta que:

a) A maior fatia do emprego, nos estabelecimentos de caráter ambulatorial (cerca de $78 \%$ em 1984), está alocada nos governos estaduais e munici- 
pais e, até mesmo, na administração federal. Cerca de $41 \%$ dos ocupados em estabelecimentos hospitalares (com internação), também, se encontram no setor público. Assim, o setor público detinha $52 \%$ do emprego em saúde, no ano de 1984;

b) apesar de aglutinar $48 \%$ dos postos de trabalhos envolvidos nessa atividade social, o setor privado tem sido financiado tanto em seu investimento como em seu custeio, pelo gasto público. A ampliação da rede privada lucrativa, de serviços de saúde, foi financiada por fundos de investimentos públicos com o Fundo de Apoio ao Desenvolvimento Social FAS, ao longo dos anos 70 . O custeio dessa mesma rede tem sido mantido, em parte, pelos contratos, convênios e credenciamentos do INAMPS. Outra parte tem seu suporte nas isenções de arrecadação de imposto de renda da pessoa física e jurídica, com gastos privados em saúde. Portanto, são as decisões tomadas no setor público que determinam, em última instância, a dinâmica do emprego nesse setor.

DISTRIBUIÇÃO DOS EMPREGOS EM SAÚDE NO BRASIL, SEGUNDO A NATUREZA DA ENTIDADE MANTENEDORA $1982-1984$

\begin{tabular}{lcccccc}
\hline \multirow{2}{*}{$\begin{array}{l}\text { ANOS DE } \\
\text { REFERÊNCIA }\end{array}$} & \multicolumn{3}{c}{ NATUREZA DA ENTIDADE MANTENEDORA } \\
\cline { 2 - 7 } & \multicolumn{2}{c}{ TOTAL } & \multicolumn{2}{c}{ PÚBLICA } & \multicolumn{2}{c}{ PRIVADA } \\
\cline { 2 - 7 } & ABS & $\%$ & ABS & $\%$ & ABS & $\%$ \\
\hline TOTAL & & & & & & \\
1982 & 854.344 & 100,0 & 418.174 & 48,9 & 436.170 & 51,1 \\
1984 & 931.949 & 100,0 & 487.660 & 52,3 & 444.289 & 47,7 \\
COM INTERNAÇÃO & & & & & & \\
1982 & 614.563 & 100,0 & 230.216 & 37,5 & 384.347 & 62,5 \\
1984 & 648.033 & 100,0 & 265.545 & 41,0 & 382.488 & 59,0 \\
SEM INTERNAÇÃO & & & & & & \\
1982 & 239.781 & 100,0 & 187.958 & 78,4 & 51.823 & 21,6 \\
1984 & 283.916 & 100,0 & 222.115 & 78,2 & 61.801 & 21,8 \\
\hline
\end{tabular}

Fonte: IBGE, Pesquisa de Assistência Médico-Sanitária.

Para entender o mercado de trabalho, em saúde, na conjuntura recente, vale a pena tecer algumas consideraçöes sobre a dinâmica do emprego em geral, e no setor público. Após o período conhecido por milagre econômico (1968-1973), a economia brasileira passou a apresentar níveis de crescimento positivos, embora decrescentes, em relação aos patamares anteriores. Dados da Relação Anual de Informações Sociais RAIS ${ }^{7}$, indicam que, apenas disso tudo, o emprego formal 
continuou a crescer, a uma taxa geométrica anual de $14,1 \%$, entre 1976 e 1980. Neste mesmo período, o emprego em saúde cresceu a taxas, ligeiramente, inferiores (13,2\% ao ano). Com o advento da crise econômica, a partir de 1979, os níveis de emprego começaram, rapidamente, a declinar. Entre 1980 e 1983, o crescimento do nível de empregos formal cai para $1,3 \%$ ao ano, sendo que, na indústria de transformação, houve perda absoluta de postos de trabalho, com um crescimento geométrico de $-5,2 \%$ ao ano.

Enquanto a economia sofria uma de suas maiores crises, o emprego, no setor governo, crescia a $9,7 \%$ ao ano, entre 1980 e 1983. Por motivos diversos dos que levaram Roosevelt a adotar estratégias Keynesianas de emprego, através do setor público, nos EUA dos anos 30, o Estado brasileiro tem utilizado, eventualmente, sua máquina empregatícia no sentido anticíclico, nos períodos de crise econômica, tal como ocorreu, entre 1980 e 1983 . Eleições, clientelismo político, empreguismo, reestruturação parcial de órgãos e funções dos governos, em diversas instâncias da administração pública têm sido, algumas das várias formas que o Estado encontrou para manter acesso, mesmo que, casualmente, o ritmo de absorção de empregos, num período de vacas magras para a maior parcela do setor privado. Embora o aumento dos níveis de ocupação, nos órgãos governamentais, tenha sido contrabalançado por uma queda nos salários reais do setor público, tal tendência pressionou, em larga escala, os patamares de gasto do Governo, levando a uma elevação de relação carga tributária/PIB e a um aumento do déficit público, nos anos de crise.

Ao lado desse crescimento do emprego no Governo, os postos de trabalho em saúde se multiplicaram a uma taxa de $15,5 \%$ ao ano entre, 1980 e 1983 . Embora tenham sido as atividades públicas de saúde as que mais puxaram o crescimento do emprego no período (17,6\% ao ano), os postos de trabalho, no setor privado, apresentaram forte dinamismo $(10,6 \%$ ao ano), de onde se conclui que os mecanismos públicos de custeio das atividades privadas de saúde foram importantes elementos da dinâmica do emprego, no setor.

Com essa performance, o setor saúde, que respondia por $3,5 \%$ dos empregos formais em 1976, passa a englobar 5,0\% do total de postos de trabalho existentes no país, em 1983*.

\section{MUDANÇA NO PERFIL \\ DAS EQUIPES DE SAÚDE}

Além de rápido aumento do total de empregos em saúde registrados no período, destaca-se o caráter específico do crescimento de algumas categorias profissionais. Como foi visto, a década de 70 notabilizou-se pela maciça participação de categorias polares, como médico e atendente, na composição das equipes de saúde. Pode-se dizer que, em 1977, estas duas categorias representaram $67,5 \%$ do total de postos de trabalho em saúde, definidos conforme os dados da Tabela 3. Informações mais recentes apontam para uma reversão dessa tendência. Em 1984, estas categorias cobriam, somente.
* Estas relaçöes foram obtidas pela divisão entre o número de postos de trabalho registrados nas estatisticas da AMS (relativas ao setor saúde) e da RAIS (Total de empregos formais). 
$58,4 \%$ dos empregos definidos. Pode-se dizer, portanto, que a polarização, entre profissionais de nível superior (médicos), e profissionais desqualificados (atendentes), tem se reduzido, recentemente, abrindo espaço para uma maior participação dos profissionais de nível médio. Assim, os empregos relacionados às categorias de técnico de laboratório e auxiliar de enfermagem passam de $14,4 \%$ para $17,8 \%$ dos postos de trabalho, nas categorias definidas, entre 1977 e 1984, respectivamente.

TABELA 3

DISTRIBUIÇÃO E CRESCIMENTO ANUAL DO EMPREGO EM SAÚDE

PARA CATEGORIAS TÍPICAS $(* *)$

BRASIL 1977 - 1984

\begin{tabular}{lrrrrrrrr}
\hline \multirow{2}{*}{ CATEGORIAS } & \multicolumn{2}{c}{1977} & \multicolumn{2}{c}{1978} & \multicolumn{2}{c}{1979} & \multicolumn{2}{c}{1980} \\
\cline { 2 - 9 } PROFISSIONAIS & \multicolumn{1}{c}{ ABS } & $\Delta \%$ & ABS & $\Delta \%$ & ABS & $\Delta \%$ & ABS & $\Delta \%$ \\
\hline Medicos & 116.460 & 10,2 & 127.305 & 9,3 & 132.882 & 4,3 & 146.091 & 9,9 \\
Odontólogos & 12.794 & 9,0 & 14.082 & 10,0 & 15.526 & 10,2 & 16.696 & 7,5 \\
Enfermeiros & 12.107 & $-1,0$ & 13.104 & 8,2 & 13.342 & 1,8 & 15.158 & 13,6 \\
Téc. Laboratório & 5.412 & 7,2 & 7.509 & 38,7 & 8.092 & 7,8 & 9.458 & 16,9 \\
Aux. Enfermagem & 49.485 & 12,0 & 53.583 & 8,3 & 59.257 & 10,6 & 64.227 & 8,4 \\
Atendentes & 140.273 & 13,1 & 158.241 & 11,3 & 166.660 & 5,3 & 176.891 & 6,1 \\
TOTAL DE (*) & & & & & & & & \\
EMPREGOS & 380.189 & 9,7 & 418.387 & 10,0 & 444.763 & 6,3 & 482.105 & 8,4 \\
\hline
\end{tabular}

\begin{tabular}{rrrrrrrr}
\hline \multicolumn{1}{c}{1981} & \multicolumn{2}{c}{1982} & \multicolumn{2}{c}{1983} & \multicolumn{2}{c}{1984} \\
\hline \multicolumn{1}{c}{ ABS } & $\Delta \%$ & ABS & $\Delta \%$ & ABS & $\Delta \%$ & ABS & $\Delta \%$ \\
\hline 155.877 & 6,7 & 171.649 & 10,1 & 180.399 & 5,1 & 194.152 & 7,6 \\
19.464 & 16,5 & 22.212 & 14,1 & 23.053 & 3,7 & 25.078 & 8,8 \\
16.144 & 6,5 & 18.047 & 11,8 & 19.592 & 8,5 & 21.766 & 11,1 \\
12.508 & 32,3 & 14.660 & 17,2 & 15.242 & 3,9 & 15.997 & 5,0 \\
73.739 & 14,8 & 85.210 & 15,5 & 89.899 & 5,5 & 100.034 & 11,3 \\
175.544 & $-1,0$ & 179.818 & 2,4 & 177.935 & $-1,0$ & 184.723 & 3,8 \\
& & & & & & & \\
512.299 & 6,3 & 555.140 & 8,4 & 576.127 & 3,7 & 646.713 & 12,2 \\
\hline
\end{tabular}

Fonte: IBGE, Pesquisa de Assistência Médico-Sanitária, 1977 a 1984.

(*) Exclui os empregos das categorias não-identificadas, que aparecem como "outros" de nivel superior, médio e elementar. Não corresponde à soma das categorias especificadas acima.

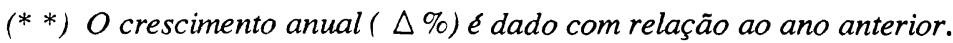


A Tabela 4 ilustra a mudança na composição das equipes de saúde, segundo a escolaridade dos empregos ocupados. Em 1978 , apenas $18,4 \%$ dos postos de trabalho correspondiam a profissionais de nível médio. A maioria dos empregos concentrava-se nas categorias de nível elementar $(47,1 \%)$ e superior (34,5\%). A principal alteração ocorrida, entre 1973 e 1984, foi o aumento da participação dos profissionais de nível médio, que passaram a representar $27,3 \%$ do total de empregos das equipes de saúde, naquele úliciro ano. Como corolário, há uma sensível redução da participação dos profissionais de nível superior $(34,5 \%$ para $29,8 \%$ ) e de nível elementar $(47,1 \%$ para $42,9 \%)$, no mesmo período.

TABELA 4

DISTRIBUIÇÃO PERCENTUAL DOS EMPREGOS DE PROFISSIONAIS DE SAÚDE POR NATUREZA E REGIME DE INTERNAÇĀO, SEGUNDO O TIPO DE PROFISSIONAIS BRASIL 1978 - 1984

\begin{tabular}{|c|c|c|c|c|c|c|c|}
\hline \multirow{2}{*}{$\begin{array}{c}\text { ANO } \\
\text { E } \\
\text { TIPO } \\
\text { DE } \\
\text { PROFISSIONAL }\end{array}$} & \multicolumn{3}{|c|}{ COM INTERNAÇĀO } & \multicolumn{3}{|c|}{ SEM INTERNAÇĀO } & \\
\hline & \multirow[t]{2}{*}{ PÚBLICO } & \multirow[t]{2}{*}{$\begin{array}{l}\text { PRIVADO } \\
\text { LUCRAT. }\end{array}$} & \multirow[t]{2}{*}{$\begin{array}{c}\text { PRIVADO } \\
\text { NĀO } \\
\text { LUCRAT. }\end{array}$} & \multirow[t]{2}{*}{ PÚBLICO } & \multirow[t]{2}{*}{$\begin{array}{l}\text { PRIVADO } \\
\text { LUCRAT. }\end{array}$} & $\begin{array}{c}\text { PRIVADO } \\
\text { NÃO } \\
\text { LUCRAT. }\end{array}$ & TOTAL \\
\hline 1978 & & & & & & & \\
\hline TOTAL & 100,0 & 100,0 & 100,0 & 100,0 & 100,0 & 100,0 & 100,0 \\
\hline - nível superior & 32,9 & 31,8 & 26,0 & 42,7 & 61,5 & 61,5 & 34,5 \\
\hline - nível médio & 25,8 & 16,1 & 16,9 & 14,5 & 16,6 & 12,3 & 18,4 \\
\hline - nível elementar & 41,3 & 52,1 & 57,1 & 42,8 & 21,9 & 26,2 & 47,1 \\
\hline \multicolumn{8}{|l|}{1982} \\
\hline TOTAL & 100,0 & 100,0 & 100,0 & 100,0 & 100,0 & 100,0 & 100,0 \\
\hline - nível superior & 25,7 & 25,7 & 20,5 & 36,3 & 53,1 & 53,1 & 28,5 \\
\hline - nível médio & 28,5 & 23,9 & 24,7 & 23,0 & 21,2 & 21,2 & 25,2 \\
\hline - nível elementar & 44,6 & 62,2 & 54,8 & 40,7 & 25,7 & 25,7 & 46,3 \\
\hline \multicolumn{8}{|l|}{1984} \\
\hline TOTAL & 100,0 & 100,0 & 100,0 & 100,0 & 100,0 & 100,0 & 100,0 \\
\hline - nível superior & 26,6 & 27,2 & 21,9 & 36,4 & 52,8 & 51,3 & 29,8 \\
\hline - nível médio & 31,5 & 25,6 & 26,3 & 25,1 & 26,0 & 25,3 & 27,3 \\
\hline - nível elementar & 41,9 & 47,1 & 51,8 & 38,5 & 21,2 & 23,4 & 42,9 \\
\hline
\end{tabular}

Fonte: IBGE, Pesquisa de Assistência Médico-Sanitária.

As prioridades definidas pela política de saúde pós-76, no campo específico dos recursos humanos, certamente, foram decisivas nessa mudança na composição interna das equipes de saúde. Desde 1976, que a ênfase na formação de recursos humanos em saúde tem sido voltada para a capacitação de pessoal de nível médio, seja em função das necessidades de expansão da rede ambulatorial, seja em decorrência do baixo nível de qualidade de atendimento prestado nos hospitais, em função da bipolarização do emprego, entre médicos e atendentes. A escolha da via supletiva de formação de pessoal de nível médio, através de programação, como o "Larga Escala", 
foi decisiva no campo das facilidades de jogar profissionais qualificados e com experiências de trabalho, no setor. Assim, muitos atendentes ou auxiliares operacionais de serviço, sem qualificação, tiveram oportunidade de ser escolarizados e receber especialização técnica, ligada à área de saúde.

O resultado dessa estratégia foi o baixo crescimento dos atendentes (31,7\% entre 1977 e 1984) e a larga expansão dos auxiliares de enfermagem (102,1\% no mesmo período).

Apesar de continuarem apresentando crescimento, as categorias de nível superior começam a perder participação relativa na composição das equipes de saúde. A ênfase, na interdisciplinariedade das equipes, tem tido efeitos na redução relativa do contingente de algumas profissões, como médicos, e na maior absorção de outras como: enfermeiros, odontólogos, nutricionistas e assistentes sociais. De fato, o número de concluintes de cursos de medicina, que chegou a $8.722 \mathrm{em} \mathrm{1978,}$ reduziu-se para 7.289 e, ao que parece, continua a cair. Em contrapartida, o número de enfermeiros formados em 1983 (4.934) foi o mais alto até aquele momento, e tudo indica que a capacidade de formação em enfermagem aumente ainda mais.

As mudanças verificadas na composição das equipes de saúde têm ocorrido, fundamentalmente, no setor público. Os estabelecimentos privados com internação, especialmente os "não lucrativos" (beneficentes e filantrópicos) continuam empregando mais da metade de seu contingente em empregos de nível elementar. $O$ aumento da participação de profissionais de nível médio, nas equipes destes estabelecimentos, responde às exigências dos convênios com a Previdência e com a iniciativa privada que, em muitos casos, exigem equipes mais bem preparadas para o estabelecimento de contratos de prestação de serviços.

Apesar do aumento do peso dos empregos de nível médio ser uma constante em todos os tipos de estabelecimentos de saúde, os de caráter ambulatorial privados continuam tendo, nos profissionais de nível superior, a maior parte de seus empregos. Isto porque o segmento de estabelecimentos privados sem, internação, não é voltado, em média, para o atendimento geral, mas sim, para a assistência em uma dada modalidade de especialização. Mesmo quando têm convênios com a previdência, as clínicas especializadas privadas, sem internação, dependem muito do especialista, particularmente, do médio, e têm, na lucratividade em cima do trabalho médico e dos exames, sua principal forma de sustentação.

\section{AMBULATORIZAÇÃO DO EMPREGO EM SAÚDE}

A ambulatorização do emprego em saúde, no Brasil, pode ser vista, de antemão, pela alta taxa de crescimento dos estabelecimentos sem internação. Entre 1978 e 1980 e entre 1980 e 1982 , este crescimento foi de $28,5 \%$ e $40,2 \%$, contra os $6,9 \%$ e $9,0 \%$ encontrados para os estabelecimentos com interCadernos de Saúde Pública, R.J., 2 (4): 409-422, out/dez, 1986 
nação, no mesmo período, respectivamente. Vale destacar que só entre 1980/82, os estabelecimentos públicos, sem internação, cresceram $61,1 \%$.

Com todo esse desempenho, é natural que o crescimento do emprego tenha acompanhado o incremento da capacidade instalada na rede ambulatorial. Em 1980 a rede, sem internação, respondia por $27,5 \%$ dos postos de trabalho do setor.

Quatro anos depois, a participação dessa rede, na absorção dos empregos, aumentou para 30,3\% A tendência à regionalização das ações de saúde, a partir das AIS, tem impulsionado ainda mais, a absorção de empregos pela rede ambulatorial, especialmente, nos Estados e Municípios.

As três tendências, aqui apontadas, representam uma reversão, com relação ao comportamento verificado na década passada. Mas, ainda persistem grandes distorçōes decorrentes da forma como foi montada a estrutura de serviços de saúde, no Brasil, dos anos 70. Estas distorções resultaram de um quadro onde, as estratégias de financiamento, a estrutura do mercado de bens e serviços do setor e os interesses privados, definiram as políticas de saúde e, em particular, de formação e distribuição de recursos humanos para o setor.

A atual permanência do modelo médico-assistencial, complexo e especializado, faz com que persista um desiquilíbrio entre a existência de profissionais voltados para operação desse modelo, e os novos profissionais a serem formados, tendo em vista o quadro de assistência médico-sanitária a ser implantada.

Apesar de terem crescido, qualitativa e quantitativamente, os recursos voltados à expansão e operação da rede básica de serviços, bem como os destinados às medidas de saúde públi$\mathrm{ca}$, ainda são insuficientes para atingir os propósitos de universalização e eqüidade, no atendimento. Mesmo assim, mais de 2.000 municípios já assinaram convênios AIS, e cerca de $13 \%$ do orçamento do INAMPS, em 1986, têm sido voltados a operar programas ligados às AIS. No entanto, permanece a histórica concentração da rede de saúde, dos gastos e dos recursos humanos, em regiōes como a Sul e a Sudeste e a relativa (e em alguns casos absoluta) escassez de recursos, nas regiōes mais carentes.

Por fim, apesar de estarem ganhando mais peso na composição das equipes, os profissionais de nível médio continuam sendo poucos e, insuficientemente, preparados para atender, de forma única e integral, os requisitos da nova política de saúde desenhada, recentemente, nas propostas da VIII Conferência Nacional de Saúde, e no movimento pró-Reforma Sanitária. Urge repensar o sistema de formação de técnicos e auxiliares para o setor, bem como redesenhar o papel do profissional universitário. Neste caso, cabe acrescentar que, o tratamento social e interdisciplinar das questões de saúde, no Brasil, exige que seja pensada uma nova relação de profissões universitárias, com novos currículos e novas formas de inserção profissional, no setor. Os currículos de medicina, em particular, devem adequar a especialização às modalidades assisCadernos de Saúde Pública, R.J., 2 (4): 409-422, out/dez, 1986 
tenciais de maior representatividade no perfil epidemiologico da população, bem como formar um maior número de generalistas voltados à operação e funcionamento da rede básica de serviços.

\section{LIÇÕES PARA A REFORMA SANITÁRIA}

A necessidade de uma amplaReformaSanitária que seja orientada para o aprofundamento das estratégias de regionalização, hierarquização e controle social, preconizadas pelas AIS, bem como para o tratamento único das açōes de alcance coletivo no campo da saúde pública, distribuição de vacinas, medicamentos e alimentos, em conjunto com a assistência médica, exige um novo desenho da política de recursos humanos.

O passado ensinou que, a submissão das políticas de saúde e, em particular, da formação, desenvolvimnto e distribuição de recursos humanos, aos sistemas de custeio, pagamento e lucratividade, foram os principais ingredientes responsáveis pela descoordenação, inadequação, multiplicidade de esforços e má distribuição dos recursos humanos em saude, hoje, exisentes no Brasil.

Portanto, tornam-se necessárias uma série de ações que possibilitem:

a) No campo da formação:

- desenhar uma nova estrutura de órgãos de desenvolvimento de recursos humanos, nas instituições públicas, estimulando à preparação de pessoal técnico para o exercício de funçōes integrais, dentro do novo modelo de atenção à saúde;

- desenvolver estruturas de formação de pessoal técnico ao nível regional, como forma de privilegiar os recursos humanos adequados às necessidades $\mathrm{e}$ características locais, no campo da saúde, e das condições sócio-econômicas;

- adequar a estrutura universitária das profissões de saúde, de forma a planejar a formação de especialistas, segundo o real quadro de necessidades. Criar incentivos para a realização de estágios, residência médica e transferência de recém-formados, para áreas mais necessitadas;

- desenvolver mecanismos de integração serviço/ensino, em todos os níveis de qualificação, tendo, como base, a investigação de modelos assistenciais localizados em espaços/populações concretas.

b) No campo da integração das políticas de recursos humanos com as políticas de saúde:

- definir, explicitamente, o papel, função e atribuição dos Estados, Municípios e distritos sanitários, na formação, desenvolvimento e distribuição dos recursos humanos em saúde;

- adotar mecanismos que incentivem o trabalho, em tempo integral ou dedicação exclusiva, especialmente, para os profissionais de nível superior, com 
vistas a minimizar a multiplicidade de empregos que, hoje, $e$ vivida por grande parte dos profissionais de saúde, no Brasil, trazendo fortes prejuízos ao atendimento e à qualidade dos serviços;

- estabelecer mecanismos contratuais que levem ao efetivo cumprimento, concomitante de carga horária, com produção mínima;

- equacionar, condignamente, a situação dos médicos credenciados, implantando forma de controle social sobre os serviços por eles prestados;

- definir critérios que promovam a resolução ágil dos problemas relacionados ao atendimento ao nivel regional e local, especialmente, nas regiōes, hoje, desprovidas de serviço público de assistência à saúde;

c) No campo dos direitos trabalhistas:

- estabelecer critérios de recrutamento e seleção ajustados à realidade dos serviços de saúde;

- criar a obrigatoriedade de concurso público para todas as instituições do setor público federal, estadual e municipal, tanto na administração direta, quanto na indireta;

- implantar planos de carreira, com possibilidades de progressão horizontal e vertical, a partir de avaliações de desempenho;

- estabelecer, gradativamente,a isonomia salarial nos serviços públicos, para todas as categorias profissionais, com vistas a equacionar problemas, hoje, enfrentados na administração de recursos humanos das AIS onde, funcionários de certas instâncias, recebem menos do que outros no desempenho de um mesmo serviço, no mesmo estabelecimento.

Tais medidas deveriam ser o ponto de partida para o estabelecimento de uma política de recursos humanos, adequada às necessidades preconizadas pela Reforma Sanitária.

Para finalizar, cabe mencionar que, grande parte dos problemas, hoje, enfrentados no campo de recursos humanos, em saúde, encontram-se atrelados à questão salarial. Ao longo dos anos de autoritarismo, os salários dos profissionais de saúde sofreram uma longa e contínua deterioração. Esta política salarial, alem de fragmentar o mercado de trabalho criou, especialmente, para os médicos e outros profissionais de nível superior, estratégias de emprego múltiplo. $\mathrm{O}$ multi-emprego foi uma decorrência do arrocho salarial. Porém, não é, simplesmente, aumentando os salários, que se resolve o problema. Os médicos do INAMPS, por exemplo, passaram a receber, desde 1985 , remuneração equivalente a 10 salários mínimos, por um emprego de 20 horas, e continuam resistindo a cumprir esta jornada de trabalho e a implantação de meios de controle, que permitam tal cumprimento. Neste caso tem que ser negociada uma solução que, aumente os salários, crie mecanismos de dedicação exclusiva a um único emprego e permita poderosas formas de controle social, sobre a jernada de 
trabalho, dos profissionais de saúde. Vale dizer, no entanto, que os profissionais de saúde, com formação de nível médio e elementar, continuam a receber salários aviltantes.

Uma política salarial digna para estes profissionais, conjuntamente, com incentivos de remuneração para trasnferência às regiōes mais necessitadas, a exemplo do que vem sendo feito pela Secretaria de Saúde do Paraná, podem ser o ponto de partida para solução desses problemas.

\section{BIBLIOGRAFIA CONSULTADA}

1. ESCOLA NACIONAL DE SAÚDE PÚBLICA. Departamento de Administração e Planejamento. Núcleo de Recursos Humanos em Saúde. Recursos humanos em saúde no Brasil: relatório parcial do projeto. Rio de Janeiro, 1983. mimeo.

2. ESTRATÉGIA de mudanças na saúde e na assistência médica: bases para a reforma sanitária. s.1., 1986. mimeo.

3. MACHADO, M. S. A participação da mulher na força de trabalho em saúde no Brasil. Belo Horizonte, DMPS/UFMG, 1986.

4. MEDICI, A. C. A força de trabalho em saúde no Brasil nos anos 70: percalços e tendências. Rio de Janeiro, ENSP, 1984. mimeo.

5. MEDICI, A. C. \& SILVA, P. L. B. Alternativas de financiamento da atençáo d saúde. Brasflia, 1986. [Trabalho apresentado na Conferência Nacional de Saúde, $8^{\circ}$. Tema Financiamento do Setor].

6. NOGUEIRA, R. P. Dinâmica do mercado de trabalho em saúde no Brasil, 1970/1983. Brasília, OPS, 1986.

7. RELAÇÃO ANUAL DE INFORMAÇÕES SOCIAIS-RAIS. Brasília, Ministério do Trabalho, 1976, 1979, 1980, 1983. 